\title{
Comparison of hot-water extraction and steam treatment for production of high purity-grade dissolving pulp from green bamboo
}

\author{
Xiaolin Luo $\cdot$ Jing Liu $\cdot$ Haisong Wang • \\ Liulian Huang $\cdot$ Lihui Chen
}

Received: 28 November 2013/Accepted: 9 March 2014/Published online: 26 March 2014

(C) Springer Science+Business Media Dordrecht 2014

\begin{abstract}
The performance of hot-water extraction (HWE) and steam treatment (ST), followed by kraft pulping were compared for production of high puritygrade dissolving pulp from green bamboo. With the same prehydrolysis intensity (represented by the P-factor), the fractionation efficiency of HWE is far lower than that of ST. Because of lower removal of non-cellulosic components, the solid residue from HWE (even at approximately double the prehydrolysis intensity, $\mathrm{P}$-factor $=1,379$ ) required more active alkali (AA) during kraft pulping to obtain a cellulose purity equivalent to that achieved by the ST (Pfactor $=756$ )-kraft process. To reach equivalent hemicellulose removal, HWE required more severe intensity than ST. However, FTIR and SEM characterizations of solid residue confirmed that intensified HWE resulted in significant lignin condensation. Antagonistic effects of hemicellulose removal and
\end{abstract}

Electronic supplementary material The online version of this article (doi:10.1007/s10570-014-0234-2) contains supplementary material, which is available to authorized users.

X. Luo · J. Liu · L. Huang · L. Chen $(\bowtie)$

College of Material Engineering, Fujian Agriculture and Forestry University (FAFU), Fuzhou 350002, China e-mail: fafuclh@163.com

X. Luo $\cdot$ H. Wang $(\bowtie)$

Key Laboratory of Biofuel, Qingdao Institute of

Bioenergy and Bioprocess Technology, Chinese Academy of Sciences, Qingdao 266101, China

e-mail: wanghs@qibebt.ac.cn lignin condensation extent on subsequent kraft pulping were therefore more apparent in HWE than that in ST. Under the same kraft pulping conditions, lignin condensation from a severely intensified HWE process (P-factor $=2,020)$ caused greater cellulose yield and viscosity loss than that found for ST. Finally, at a given residual pentosan or lignin content, the cellulose yields from all HWE-kraft pulps were about $3 \%$ lower than those from ST-kraft pulps. Consequently, based on an optimally setup chlorine dioxide bleaching stage, a cellulosic pulp with alpha-cellulose content of $97.6 \%$ and viscosity of $927 \mathrm{~mL} / \mathrm{g}$ was successfully produced from a ST-kraft pulp (P-factor $=756$, AA $=19 \%)$.

Keywords Prehydrolysis - Lignin condensation · Hemicellulose removal . Dissolving pulp · Green bamboo

\section{Introduction}

Because of the unstable supply of global fossil resources, environmental concerns, the superior physiological properties of cellulose fiber compared to those of synthetic fibers (e.g. polyester and polyamide, etc.) and declining cotton production, ways of producing cellulosic fibers (e.g. viscose and Lyocell) from forest resources (wood and non-wood) are gaining worldwide attention (Sixta et al. 2013). To make downstream processing stages of renewable textile fibers production more stable, dissolving pulps 
are generally characterized as being pulps with high cellulose content and minimum amounts of noncellulosic impurities (such as alien polysaccharides, extractives and inorganics) (Hinck et al. 1985).

To reach these requirements, many post-treatments, including cold caustic extraction (CCE) (Köpcke et al. 2010), treatment with metal complexes (e.g. cupriethylenediamine or nitren, which is a Nickel complex) (Puls et al. 2006), ionic liquid based co-solvents (Froschauer et al. 2013) and enzyme pretreatments (Bajpai and Bajpait 2001; Ibarra et al. 2009), have been combined with a full bleaching sequence to investigate their ability to convert paper-grade kraft pulps into dissolving pulps. Although these methods simplified production steps and also resulted in high cellulose purity, ineffective removal of the residual solvent or chemicals from the pulp and high operational costs (in particular for solvent recovery and wastewater treatment) made them industrially unattractive. Moreover, the dissolution of hemicellulose into black liquor during kraft cooking makes it more difficult to convert a dissolving-pulp production process into a viable integrated forest biorefinery process (Van Heiningen 2006).

Within the forest biorefinery concept, the selectively separation of hemicellulose from biomass is crucial stage in the production of dissolving pulp. Up until now, numerous methods, including dilute mineral acid (Al-Dajani et al. 2009; Jahan 2008) and alkali (Walton et al. 2010) prehydrolysis, hot-water extraction (HWE) (Borrega et al. 2013), organosolv (Fink et al. 2004), and acid/alkaline sulfite and steam treatments (STs) (Hinck et al. 1985; Sixta 2006), have been subjected to extract hemicelluloses from the lignocellulosic feedstock prior to kraft pulping. However, acidic extraction methods are associated with uncontrollable equipment corrosion problems, significant lignin condensation, high yield loss and polydispersity of cellulose, although they do increase the solubilization rate of hemicellulose than that purewater extraction does (Al-Dajani et al. 2009; Fink et al. 2004). Near-neutral organic solvent processing (methanol or ethanol/water systems) and alkali extraction can overcome these shortcomings; unfortunately, the recyclability and costs of solvents for the former process (Fink et al. 2004), and the low selectivity of the latter process (Helmerius et al. 2010; Walton et al. 2010) impair their further development. Therefore, because it uses water as the sole reagent and because it is based on existing equipment and practical production experience within the kraft pulp industry, it is not surprisingly that the water-based prehydrolysis-kraft (PHK) process is currently regarded as the most environmentally friendly and industrially scalable route to produce dissolving pulp as part of a forest biorefinery (Borrega et al. 2013; Li et al. 2010; Sixta 2006).

Depending on whether they use liquid water or steam, water-based prehydrolysis processes are further subdivided into HWE and ST. To date, carbohydrate dissolution profiles and kinetics (Amidon and Liu 2009; Li et al. 2010), characterization of prehydrolyzate and solid residues (Leschinsky et al. 2008a, b; Ma et al. 2013), process mass balance (Saeed et al. 2012) and effects of HWE on subsequent kraft pulping (Sixta 2006; Yoon and Van Heiningen, 2008) have been systematically studied. Also, a kinetic study of pentosan solubility during ST (Luo et al. 2013b) and comparisons of HWE and ST for sugar recovery and ethanol production (Allen et al. 2001; Kemppainen et al. 2012; Laser et al. 2002 and Perez-Cantu et al. 2013) have also been conducted. However, at severe prehydrolysis intensity, the relationship between hemicellulose removal and lignin condensation extent during HWE and ST, and their antagonistic effects on subsequent kraft pulping were rarely investigated in the research fields of bio-ethanol production and dissolving pulp production. The objectives of this study are (1) to clarify these relationships and (2) to coordinate the intensity and active alkali (AA) used in the processes of water-based prehydrolysis (HWE and ST) and kraft pulping, so as to be able to extract hemicelluloses without disrupting the dissolving pulp production process. If this can be done, then it will be an important step closer to an effective forest biorefinery.

\section{Materials and methods}

\section{Materials}

To alleviate deforestation in some countries with a scarcity of wood resources (particularly in China), non-wood forest resource (such as bamboo) have been selected to evaluate the potential of PHK processes for production of high-purity grade dissolving pulp in recent decades. Green bamboo (Dendrocalamopsis 
oldhami (Munro) $\mathrm{Ke}$ ) chips used in this study were generously provided by Nanjing Forestry (Zhangzhou City, Fujian, China). The chips were air-dried and screened to a relatively homogeneous size of $30 \mathrm{~mm} \times 15 \mathrm{~mm} \times 3 \mathrm{~mm}$. For chemical composition analysis, screened, treated chips and pulps were ground to pass a 40-mesh screen. The composition of the green bamboo was as follows: $49.6 \%$ cellulose, $17.5 \%$ pentosan, $23.1 \%$ Klason lignin, $6.8 \%$ hotwater extracts, and $1.8 \%$ ash on a dry weight basis. All chemicals used in kraft pulping and subsequent bleaching sequences were analytical reagent grade, purchased from Jingke Chemicals Co., Ltd. (Fuzhou city, China) and used as received.

Prehydrolysis

Hot-water extractions were conducted in a water bath digester $(15 \mathrm{~L})$, which was equipped with four 1.5-L stainless steel vessels (Xi' an City, China). About $150 \mathrm{~g}$ screened bamboo chips (o.d., oven-dried) and required amount of water were loaded into a vessel to reach the ratio of water to bamboo chips (o.d.) of 3:1. Sealed vessels $(1.5 \mathrm{~L})$ were then mounted into a $15 \mathrm{~L}$ pulping digester, heated externally via water and rotated at a speed of $2.5 \mathrm{rpm}$ to provide the mixing during prehydrolysis. Four reaction temperatures $(150,160,170$ and $180^{\circ} \mathrm{C}$ ) and durations (30, 60, 90 and $\left.120 \mathrm{~min}\right)$ were chosen to pre-extract bamboo chips. At the end of the extraction, the external water used to heat the vessels was immediately drained through a bottom valve. Afterwards, the vessels were quickly taken out and further cooled to room temperature with tap water. The solid residue and hydrolysate were collected in a Büchner funnel on filter paper. Resultant solid residues were washed three times using tap water to remove soluble sugars. After making the balance of the moisture of the washed solid residue, solid residue yield was determined gravimetrically by drying a small part of representative samples at $105^{\circ} \mathrm{C}$ overnight. The $\mathrm{pH}$ of the collected hydrolysate was also determined on a pH meter. The remaining solid residues were stored in a refrigerator at $4{ }^{\circ} \mathrm{C}$ for additional experiments.

Steam treatments were conducted in a custom-built device (shown in Supplemental A), the main components of which were a stainless reactor (NU-4, Japan Chemical Engineering and Machinery Co. Ltd., Osaka, Japan) and a steam generator (LHSO.1-1.6-Y.Q, Anyang Fu Shi De Co. Ltd., Henan City, China). The internal volume of this the reactor was about $0.3 \mathrm{~L}$. Approximately $150 \mathrm{~g}$ (o.d.) of screened green bamboo chips were firstly placed in a stainless mesh made cylinder container and then introduced to the reactor. The reactor was sealed and the hot steam at a pressure of 2.0 Mpa was jetted into the reactor from the top to begin the treatment. Inner air was released briefly by opening the valve at the bottom of the reactor three times; this air was not collected by the condensate water container (CWC). After fresh steam was injected into the reactor for $3 \mathrm{~min}$ (inner temperature $100{ }^{\circ} \mathrm{C}$ ), condensate water was slowly released into the $\mathrm{CWC}$ (which was kept in an ice-water bath) by opening the valve at the bottom of the reactor. Then, the reactor was heated directly by steam to the desired temperature (in the range 160-200 ${ }^{\circ} \mathrm{C}$ ). When the temperature reached target value $\left( \pm 2{ }^{\circ} \mathrm{C}\right)$, the treatment time (in the range 0-60 $\mathrm{min}$ ) was recorded immediately. Once half of the reaction time had passed, condensate water was carefully drained into the CWC, as before. At the end of the ST, the steam inlet valve was immediately closed and the exhaust valve on the top of the reactor was quickly opened to release the inner pressure. The mesh cylinder containing treated bamboo chips was then removed from the reactor. Residual condensate water in reactor was immediately discharged into the container, which still stayed in ice water bath. Finally, the ratio of condensate water to bamboo chips (o.d.) of STs was estimated to be approximately $3: 1$ via a gravimetrical method. Treated bamboo chips and condensate water were sealed in a plastic bag and bottle, respectively, and stored at $4{ }^{\circ} \mathrm{C}$ for further use.

It should be noted that the steam inlet valve on the top of the reactor and the exhaust valve at the bottom of the reactor were simultaneously opened during the process of draining the condensate water (Supplemental A). The operation time for discharging the condensate water is less than $1 \mathrm{~min}$ and the fluctuation of the reaction temperature was kept within operating error $\left( \pm 2{ }^{\circ} \mathrm{C}\right)$. Reheating the reactor from ambient temperature to the reaction temperature was therefore avoided. From the point of view of kinetics, the fundamental kinetics of the chemical reactions involving main components in green bamboo were at least not influenced by reaction temperature and time. The only difference between HWE and ST would lie in the different diffusion efficiencies of degraded carbohydrate and lignin, probably caused by the presence of condensed lignin or pseudo lignin (see the "Results and 
discussion" for further description). Considering the assumption used to develop the P-factor, the impact of mass transfer itself on kinetic model development was ignored. By substituting a new value of activation energy [Refer to Supplemental B (part 2)], the intensities of both ST and HWE can be described by the P-factor.

\section{Kraft pulping}

The kraft pulping steps were conducted in an oil bath digester (YYQ-10-1.25, Nanjing Jiezhen Science \& Technology Development Co. Ltd., Nanjing City, China). Ten 1.5-L stainless steel pressure vessels were fixed on a shelf and rotated at $3 \mathrm{rpm}$ to mix bamboo chips and chemicals during cooking. The shelf was mounted in a large pulping digester $(200 \mathrm{~L})$; fixed vessels were heated externally using oil. Pre-extracted bamboo chips (100 g o.d.) were added into each stainless vessel and then heated to the cooking temperature at a speed of $1.5{ }^{\circ} \mathrm{C} / \mathrm{min}$. The charges of active alkali (AA, calculated as $\mathrm{NaOH}$ ) on preextracted chips (o.d.) ranged from 21 to $23 \%$ for HWE and 15 to $21 \%$ for ST. The sulfidity (S), ratio of liquor to chip (o.d., L/W), cooking temperature $(\mathrm{T})$ and duration $(\mathrm{t})$ for all kraft pulping experiments were fixed at $26 \%, 4,170{ }^{\circ} \mathrm{C}$ and $60 \mathrm{~min}$, respectively. Kraft pulping was terminated by quenching the vessels in an ice-water bath. Finally, the cooked chips were disintegrated, washed and subsequently screened using a flat with a $0.15 \mathrm{~mm}$ mesh. The screened pulps were collected in different sealed polyethylene bags for further measurement and bleaching experiments.

\section{Elemental-chlorine free (ECF) bleaching}

Two elemental-chlorine free (ECF) bleaching sequences, $D_{1} E_{2}\left(D_{1}\right.$ and $D_{2}$ represent the first and second stages of chlorine dioxide bleaching, $\mathrm{E}$ is an alkaline extraction) and DEQP (Q and P denotes as chelation treatment and hydrogen peroxide bleaching) were used to refine the kraft pulps. The active chlorine charges (ACCs) for $\mathrm{D}_{1}$ and $\mathrm{D}_{2}$ ranged from 1.14 to $2.28 \%$, and 0.20 to $1.00 \%$, respectively. In addition to ACCs, the temperature, duration, consistency and ratio of $\mathrm{NaOH}$ to $\mathrm{ClO}_{2}$ (calculated as ACC) were set as $75{ }^{\circ} \mathrm{C}, 2 \mathrm{~h}, 10 \%$ and $1: 2$, respectively. Alkaline extraction (E) was performed with $2 \% \mathrm{NaOH}$ (based on o.d. pulps) at $60^{\circ} \mathrm{C}$ for $1 \mathrm{~h}$. Pulp consistencies for $\mathrm{E}$ and Q were both about $4 \%$. Chlorine dioxide charge (calculated as ACC) of D in the DEQP bleaching sequence was $1.90 \%$ (based on o.d. pulps). Other bleaching conditions for $\mathrm{D}$ and $\mathrm{E}$ in the DEQP bleaching sequence were the same as those for $D_{1}$ and $\mathrm{E}$ in the $\mathrm{D}_{1} \mathrm{ED}_{2}$ bleaching sequence. The $\mathrm{Q}$ stage was conducted with $0.2 \%$ ethylenediamine tetraacetic acid (EDTA, based on o.d. pulps) at $60{ }^{\circ} \mathrm{C}$ for $30 \mathrm{~min}$. By adjusting the initial $\mathrm{pH}$ of the prepared pulp suspension to $9-11$, the pulp from stage of Q $(10 \%$ consistency) was further treated with $\mathrm{H}_{2} \mathrm{O}_{2}(2.5 \%$ on o.d. pulp) and $\mathrm{MgSO}_{4}(0.03 \%$ also on o.d. pulp) at $90{ }^{\circ} \mathrm{C}$ for $4 \mathrm{~h}$. The pulp from each bleaching stage was washed in a Büchner funnel with deionized water until the $\mathrm{pH}$ of the filtrate was close to neutral.

Analytical methods

A colorimetric method using orcinol-ferric chloride reagent was used to measure pentosans in bamboo chips and resultant pulps (Tappi standard, T223cm01). The total cellulose contents in pre-hydrolyzed bamboo chips and alpha-cellulose contents in kraft and bleached pulps were determined according to two other Tappi standards T201wd-76 and T203cm-99, respectively. Klason lignin and ash contents in bamboo chips and kraft and bleached pulps were determined according to National Renewable Energy Laboratory (NERL) Analytical Procedures. Residual alkali concentration (RAC) in black liquor was titrated with $0.1 \mathrm{~mol} / \mathrm{L}$ hydrochloric acid, as described elsewhere (Luo et al. 2012). The brightness of the bleached pulps was evaluated by the ISO 2470 method. In addition, the cupriethylenediamine (CED) method (T254cm-00) and Tappi Useful Method (UM246) were used to measure the intrinsic viscosities and kappa numbers, respectively, of kraft and bleached pulps. The prehydrolysis, kraft pulping and corresponding measurements were conducted in duplicate for each sample; the average is reported here.

Untreated, hot-water extracted and steam-treated bamboo chips were vacuum dried and finely ground using a high speed grinder to pass an 80-mesh $(0.2 \mathrm{~mm}$ opening). FTIR spectra of these powdery samples were obtained on an FTIR spectrophotometer (ThermoNicolet AVATAR 380, USA) using a $\mathrm{KBr}$ disc containing $1 \%$ finely ground sample. The spectra were recorded in the range of $4,000-400 \mathrm{~cm}^{-1}$ using an accumulation of 50 scans with a resolution of $4 \mathrm{~cm}^{-1}$. 
Cross sections with a 1-2 mm long were taken from untreated, hot-water extracted and steam-treated bamboo chips and then vacuum dried. Selected samples were sputter-coated with gold and imaged by a JEOL JSM-7500F SEM (München, Germany) under high vacuum operation mode at $3.0 \mathrm{kV}$.

\section{Results and discussion}

Prehydrolysis induced change in chemical components

Because of increased porosity, partial degradation of lignin and cleavage of alkali-resistant carbohydratelignin bonds, prehydrolysis does indeed improve delignification rate of lignocelluloses during alkali pulping (Sixta 2006). Thus it is preferable to consider the severities of prehydrolysis and pulping simultaneously rather than just using the $\mathrm{H}$-factor alone, particularly to control the kappa number of the PHK pulps. From a mathematical perspective, the algebraic expressions for $\mathrm{P}$-factor and $\mathrm{H}$-factor are obviously quite similar, while that for the severity factor $\left(R_{0}\right)$ is somewhat different [Supplemental B (part 2)]. Based on this consideration, recently, Duarte et al. (2011) introduced $\mathrm{P}$-factor and $\mathrm{H}$-factor into the traditional delignification kinetic model. Good agreement between the predicted and experimental kappa numbers of PHK pulps with different prehydrolysis severities was achieved. As the $\mathrm{H}$-factor and $\mathrm{P}$-factor are essentially the same [see Supplemental B (part 2)], the former can also be used to describe the prehydrolysis process if its Ea is modified to be that obtained by fitting the kinetics of pentosan dissolution from the corresponding raw materials. However, in the chemical pulping industry, the traditional $\mathrm{H}$-factor, even today, is used for process control purposes (Luo et al., 2013a). To avoid confusion of terminology, the P-factor with modified Ea [as discussed in detail in Supplemental B (part 2)] will be referred to as the reaction ordinate of prehydrolysis in this paper.

Based on the modified P-factor (Supplemental B), changes in solid residue yields during HWE and ST of green bamboo are shown in Fig. 1a. It was clear that the more severe the auto-hydrolysis, the lower solid residue yields of green bamboo for both HWE and ST. Under the same P-factor, however, ST resulted in a lower solid residue yield compared with that from
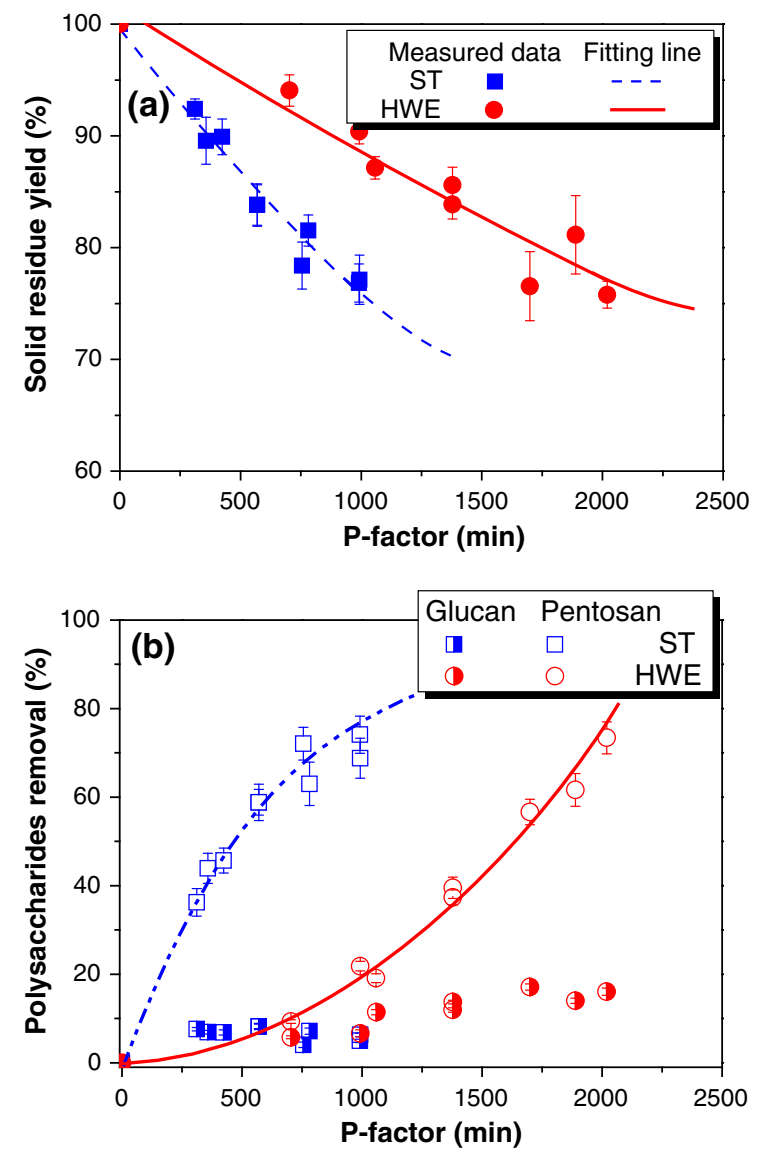

Fig. 1 Comparisons of P-factor-dependent a solid residues yield and $\mathbf{b}$ polysaccharides removal between hot-water extractions (HWEs) and steam treatments (STs). Fitting parameters of solid residues yield data using Eq. (4) listed in Supplemental B (Part 2) (ST: $\alpha=99.55 \pm 1.08, \quad \beta=$ $-2.74(\mathrm{E}-4) \pm 1.795(\mathrm{E}-5), \mathrm{R}^{2}=0.9618$; HWE: $\alpha=101.51$ $\left.\pm 1.84, \beta=-1.36(\mathrm{E}-4) \pm 1.403(\mathrm{E}-5), \mathrm{R}^{2}=0.9183\right)$

HWE. For example, by intensifying the P-factor from 0 to 992 ( $\mathrm{min}$ ), the solid residue yield of green bamboo were $77.1 \%$ for ST versus $90.4 \%$ for HWE (Fig. 1a).

To attribute the yield loss of bamboo chips to the dissolution of individual components, the P-factordependent pentosan removal was investigated for both HWE and ST (Fig. 1b). For a P-factor $<1,000$ (min), ST removed more pentosan than HWE did. With a P-factor of 992 (min), about triple the amount of pentosan was removed by ST compared to that of HWE (Fig. 1b). However, the higher yield loss of green bamboo chips was not only because of ST induced pentosan removal (on o.d. bamboo chips), because, compared with HWE, over $13 \%$ yield loss of green bamboo chips was achieved by ST at a P-factor of 992 


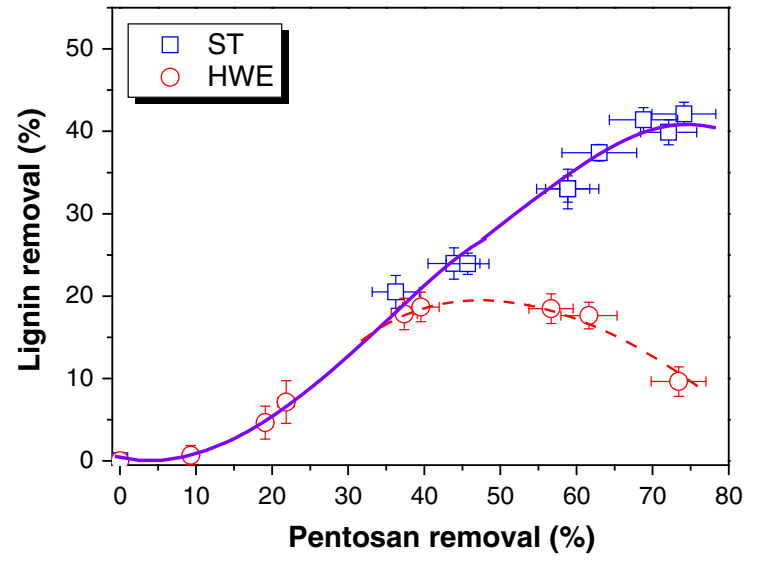

Fig. 2 Correlation between lignin and pentosan removal during hot-water extractions (HWE) and steam treatments (ST) of green bamboo

(min), while the corresponding pentosan removal was only $9 \%$ (on o.d. bamboo chips). Meanwhile, although glucan loss was slightly increased after conducting severe auto-hydrolysis (P-factor $>1,000$ ) during HWE, it remained almost constant $(3 \%$, on o.d. bamboo chips) for both HWE and ST at the P-factors from about 200 to 1,000 . Therefore, in addition to the gain of pentosan removal caused by ST, the difference in yield loss between HWE and ST must also be attributed to a difference in lignin removal.

The correlation between lignin and pentosan removal during HWE and ST of green bamboo was examined next. As shown in Fig. 2, lignin removal was close to zero for both HWE and ST, while the pentosan removal was below $10 \%$. At higher amounts of pentosan removal, the lignin removal increased continuously during the ST process, suggesting that the rate of lignin deposition on the surface of bamboo chips was lower than the release rate of lignin from the chips into the condensate water during ST. On the contrary, lignin removal from HWE showed a gradual transition between two phases, a gradual increase and then a slight decrease (Fig. 2). This implies that the lower lignin removal found for HWE is probably caused by lignin condensation or reprecipitation during prehydrolysis (Fig. 2), which also hinders the mass transfer efficiency of hemicellulose and its final extraction.

\section{Characterization of solid residues and hydrolysates}

For a given reaction temperature and duration, numerous studies (Amidon and Liu 2009; Borrega

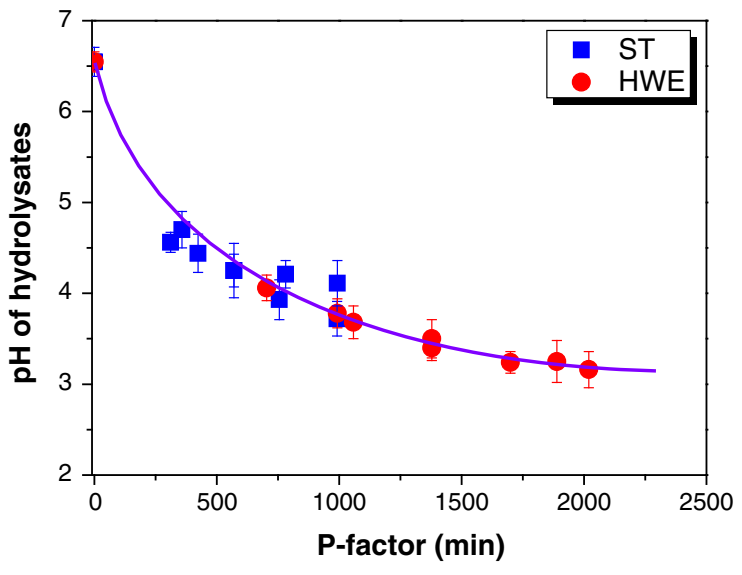

Fig. 3 P-factor-dependent $\mathrm{pH}$ values of hydrolysates from hotwater extraction (HWE) and steam treatment (ST) of green bamboo

et al. 2013; Li et al. 2010; Luo et al. 2013b) have demonstrated that the hemicellulose removal efficiency during prehydrolysis at a particular liquor to wood ratio is mainly dependent on the acidity of the reaction medium, physicochemical structure and chemical composition of lignocellulose feedstock. When plotted against the corresponding P-factor, the $\mathrm{pH}$ values of the hydrolysates from both HWEs and STs fall onto the same curve (Fig. 3). Theoretically, the same hemicellulose removal should be achieved by these two treatments at a certain P-factor when applied to the same green bamboo chips (which are almost uniform after mechanical screening). However, this was not the case (Fig. 1b). Therefore, we hypothesize that the changes in the physicochemical structure of the green bamboo chips during prehydrolysis are very different for ST to HWE, and that these changes influence the hemicellulose mass transfer efficiency rather than its hydrolysis rate (Fig. 2).

To reveal prehydrolysis (HWE and ST) induced linkage changes between carbohydrates and lignin, and compare those caused by the different treatments, the FTIR spectra of (a) untreated, (b) hot-water extracted and (c) steam-treated bamboo chips were shown in Fig. 4. Two absorption bands at 1,160 and $899 \mathrm{~cm}^{-1}$ and another absorption at $1,335 \mathrm{~cm}^{-1}$ are usually assigned to $\mathrm{C}-\mathrm{O}-\mathrm{C}$ stretching at the $\beta-(1 \rightarrow 4)$ glycosidic linkages and in-plane bending vibration of $-\mathrm{OH}$ groups in cellulose (Liu et al. 2006). The peaks at 1,064 and $1,030 \mathrm{~cm}^{-1}$ are indicative of $\mathrm{C}-\mathrm{O}$ stretching at $\mathrm{C}-3$, and $\mathrm{C}-\mathrm{C}$ stretching and $\mathrm{C}-\mathrm{O}$ stretching at $\mathrm{C}-6$, 


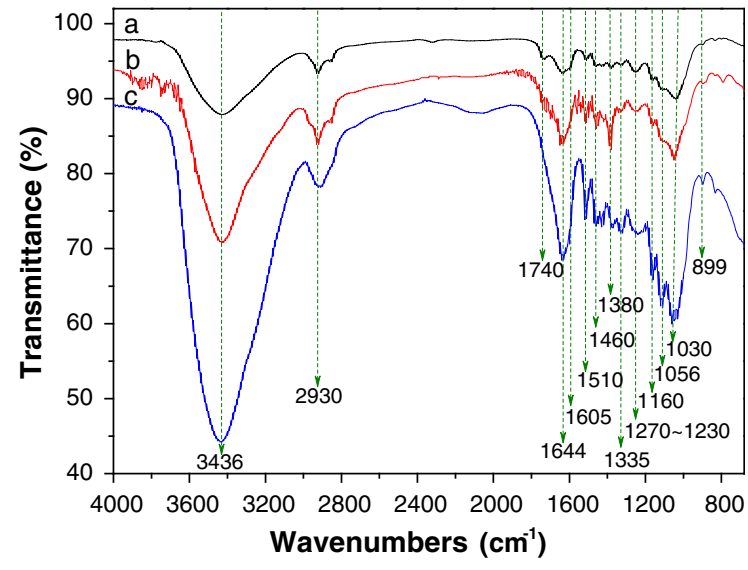

Fig. 4 FTIR spectra of $a$ untreated, $b$ hot-water extracted and $c$ steam-treated green bamboo (P-factor of 992 for both HWE and ST)

also in cellulose (Wang et al. 2009). These peaks were somewhat intensified after treated with HWE (Fig. 4, spectrum b) and more so after ST (Fig. 4, spectrum c), suggesting that either more cellulose was exposed on the surface of the solid residue or less condensations were formed during latter process. The $\mathrm{C}-\mathrm{H}$ asymmetric deformation presents at $1,380 \mathrm{~cm}^{-1}$ (Colom and Carrillo 2002). The bands at 1,605 and 1,510, $1,460,1,322,1,270$ and $1,230 \mathrm{~cm}^{-1}$ are usually associated with lignin, and include the aromatic skeletal vibration, guaiacyl and syringyl nuclei, et al. (Pandey 1999). Probably because of low lignin removal in both HWE and ST (Fig. 2), the intensities of these absorptions remained essentially constant in all the spectra.

The shoulder at $1,740 \mathrm{~cm}^{-1}$ in spectrum of (a) is from the acetyl groups of the hemicelluloses (Montane et al. 1998). The absence of this peak in spectra of (b) and (c) confirms that acetyl group had been almost completely cleaved by both HWE and ST conducted at the given conditions (P-factor of 992 for both HWE and $\mathrm{ST}$ ). This is consistent with the relatively low $\mathrm{pH}$ value of 3.6 for the hydrolysates from these two prehydrolysis processes (Fig. 3). The absorptions at 3,436 and $1,644 \mathrm{~cm}^{-1}$ are attributed to the stretching of $-\mathrm{OH}$ groups of the aliphatic moieties in cellulose and to the bending mode of the absorbed water (Liu et al. 2006), respectively. At this given $\mathrm{P}$-factor, the intensities of these two peaks were in the order: (c) $>$ (b) $>$ (a). Generally, the intensities of the absorptions of these two peaks are directly proportional to the amount of $\mathrm{OH}$ groups of the aliphatic moieties in cellulose exposed on the surfaces (outer and inner) of the bamboo chips. For untreated bamboo chips [sample (a)], cellulose is naturally tightly enfolded by hemicellulose and lignin. However, in the residues from HWE and ST (Fig. 1b), the cellulose was partially exposed. As a result, the spectral changes in these two peaks are in agreement with the chemical composition changes caused by HWE and ST (Figs. 1, 2).

Based on X-ray photoelectron spectroscopy (XPS), our previous study (Ma et al. 2013) confirmed that lignin condensation products could continually form droplet-like material on the surface of bamboo chips when the reaction time of $\mathrm{HWE}$ conducted at $170{ }^{\circ} \mathrm{C}$ was beyond $60 \mathrm{~min}$. Once the reaction time reached 120 min., the droplet-like material became a layer. This may be one reason for the different diffusion efficiencies of the degraded products (mainly hemicellulose and lignin) that formed within the bamboo chips during HWE and ST. To avoid repeated characterization, the surfaces of (a) untreated, (b) steamtreated and (c and d) hot-water extracted green bamboo were only characterized by SEM (Fig. 5). An ordered cell-wall structure was observed in the cross-section of untreated bamboo chips (Fig. 5a); this structure was was significantly disrupted by HWE and slightly smoothed by ST. The outer and inner surfaces of the hot-water extracted bamboo chips were covered by some powder-like materials (Fig. 5c, d), whereas the corresponding surfaces of the ST induced sample look relatively smooth (Fig. 5b). According to our previous XPS analysis (Ma et al. 2013) and other research reported by Sannigrahi et al. (2011) and Leschinsky et al. (2008a, b), these powder-like materials may be mainly composed of condensed lignin and a small amount of pseudo-lignin (the condensation of carbohydrate and lignin degradation products). This material would not only impede the dissolution of lignin itself, but also decrease the mass transfer efficiency of broken hemicellulose fragments during the prehydrolysis process. Therefore, in addition to greater retention of non-cellulosic components in HWE solid residue, this confirms that the FTIR bands at 3,436 and $1,644 \mathrm{~cm}^{-1}$, and 1,160 and $899 \mathrm{~cm}^{-1}$ (Fig. 4b) were also partially from lignin condensation products covering on the surface of cellulose.

We believe that the main reasons why ST is far less affected by these undesirable reactions are because of how the process occurs. Firstly, the steam used in ST has a higher permeation rate compared with that of the 

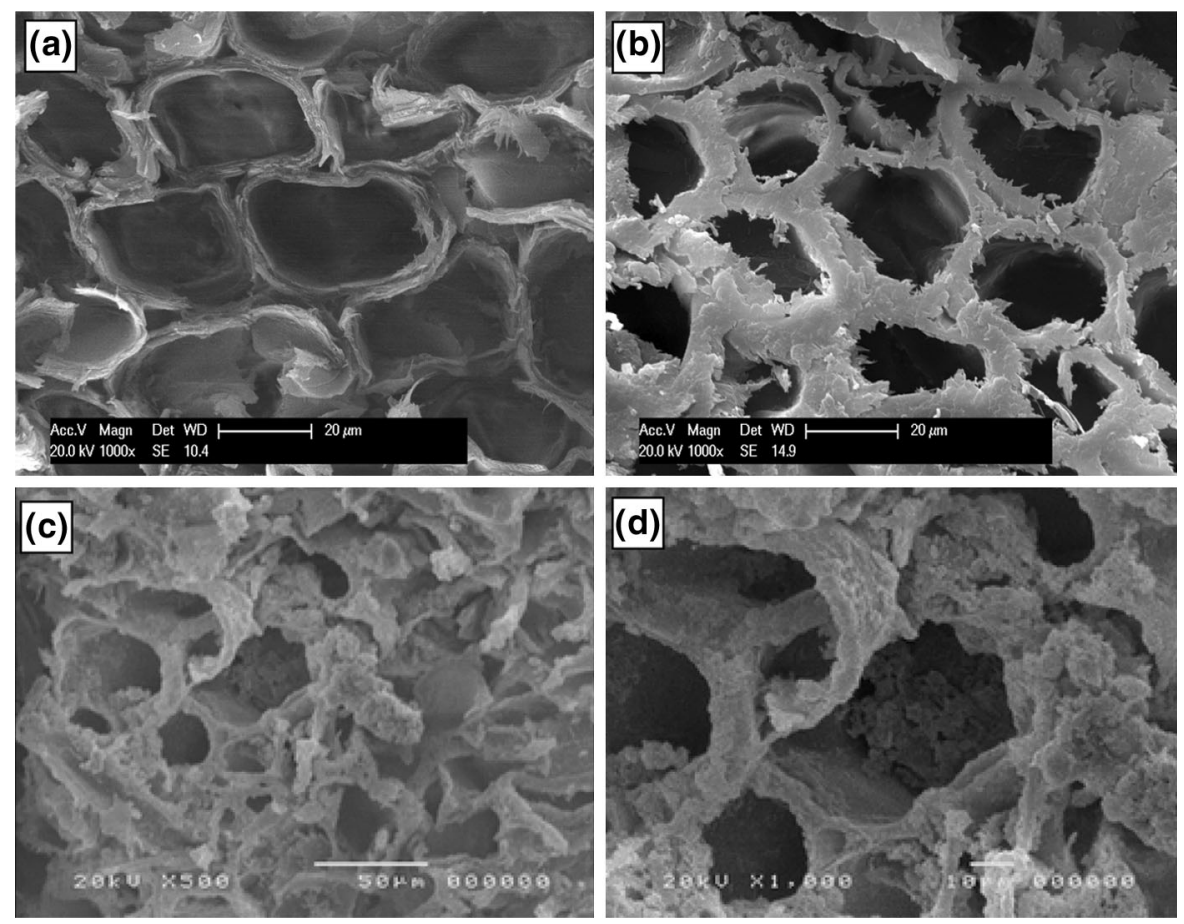

Fig. 5 SEM images of a untreated, b steam-treated and $\mathbf{c}$ and $\mathbf{d}$ hot-water extracted (from Ma et al. 2011) green bamboo (P-factor of 992 for both HWE and ST)

liquid water in HWE (Luo et al. 2013b), thus resulting in more porous bamboo chips. This kind of structure improves hemicellulose dissolution and reduces in situ condensation of broken lignin and carbohydrates that may have remained in the chips. Secondly, draining the condensate water at two timepoints during ST (refer to the section on Prehydrolysis) leaves less dissolved lignin and carbohydrates in the reactor compared with the HWE process. With the same acidity and P-factor, as a result, the rates of condensations and reprecipitation of these fractionated substances during ST were of course lower than those during HWE. To summarize, the benefits of ST compared to HWE are lower amounts of condensed and reprecipitated lignin and higher removal of non-cellulosic compounds (Figs. 1, 2), which will definitely assist in subsequent delignification during kraft pulping.

Effect of prehydrolysis on kraft pulping

As reported earlier (Sixta 2006), charging additional AA has been regarded as a more effective way to improve the purity of PHK pulp rather than increasing the $\mathrm{H}$-factor of kraft pulping. Thus, to compare the effects of HWE and ST on the properties of unbleached dissolving pulps, three typical prehydrolyzed solid residues were subjected to kraft pulping with four levels of AA.

The conditions of kraft pulping and the properties of the corresponding pulps are presented in Table 1 . Compared to ST-kraft process, even with higher severity, the HWE-kraft process consumed more AA to obtain an unbleached dissolving pulp with the same cellulose purity. The viscosity and total yield of HWEinduced kraft pulps were also lower than those of ST. For example, as shown in Table 1, to achieve a cellulose content of about $92 \%$ (wt on o.d. pulp), the charge of AA was $23 \%$ for HWE-1 versus $19 \%$ for ST-2. Meanwhile, pulp viscosity and total yield of the former were lower than that of the latter by about 1 and 168 units ( 32.8 vs. $33.9 \%$ and 860 vs. $1,028 \mathrm{~mL} / \mathrm{g}$ ) (Table 1). Similar results were also observed when comparing HWE-2 and ST-3. The differences between HWE- and ST-induced kraft pulps may be mainly attributed to the fact that: (1) low fractionation efficiency of HWE results in more retention of hemicellulose and lignin (Fig. 1b; Table 1) in the corresponding solid residue, which then consumed 
Table 1 Comparison of the effects of HWE and ST on kraft pulps composition and subsequent pulp properties

\begin{tabular}{|c|c|c|c|c|c|c|c|c|}
\hline & Sample label & HWE-1 & HWE-2 & HWE-3 & ST-1 & ST-2 & ST-3 & ST-4 \\
\hline \multirow[t]{3}{*}{ Prehydrolysis } & P-factor (min) & 1,379 & 1,379 & 2,020 & 756 & 756 & 756 & 756 \\
\hline & Pentosan removal $^{\mathrm{a}}(\%)$ & 39.5 & 39.5 & 73.4 & 72.1 & 72.1 & 72.1 & 72.1 \\
\hline & Lignin removal $^{\mathrm{a}}(\%)$ & 17.4 & 17.4 & 9.6 & 39.9 & 39.9 & 39.9 & 39.9 \\
\hline \multirow[t]{4}{*}{ Kraft pulping } & Active alkali charge ${ }^{\mathrm{b}}(\%)$ & 23 & 21 & 21 & 21 & 19 & 17 & 15 \\
\hline & Residual alkali concentration (g/L) & 15.8 & 7.0 & 13.5 & 10.3 & 5.4 & 3.8 & 2.3 \\
\hline & Kraft pulp yield ${ }^{\mathrm{b}}(\%)$ & 39.1 & 40.5 & 36.8 & 40.1 & 43.2 & 45.9 & 51.9 \\
\hline & Final pulp yield ${ }^{\mathrm{c}}(\%)$ & 32.8 & 34.0 & 27.9 & 31.4 & 33.9 & 36.0 & 40.7 \\
\hline \multirow[t]{5}{*}{ Pulp properties } & Cellulose content ${ }^{\mathrm{d}}(\%)$ & 92.0 & 91.4 & 88.5 & 93.6 & 92.9 & 91.8 & 87.0 \\
\hline & Pentosan content $^{\mathrm{d}}(\%)$ & 4.4 & 5.1 & 3.0 & 3.1 & 3.4 & 4.5 & 6.8 \\
\hline & Kappa number & 9.5 & 12.6 & 23.2 & 6.8 & 8.2 & 12.2 & 20.8 \\
\hline & Ash content ${ }^{\mathrm{d}}(\%)$ & 0.58 & 0.46 & 0.44 & 0.38 & 0.42 & 0.46 & 0.44 \\
\hline & Pulp viscosity (mL/g) & 860 & 1,019 & 758 & 972 & 1,028 & 1,237 & 1,423 \\
\hline
\end{tabular}

a On o.d. pentosan in untreated bamboo chips

b On o.d. prehydrolyzed bamboo chips

c On o.d. untreated bamboo chips

d On o.d. kraft pulp

more AA during kraft pulping (Yoon and Van Heiningen 2008); (2) cellulose viscosity and pulp yield could be dramatically decreased by alkali hydrolysis and peeling reaction if kraft pulping was conducted at high AA charge (Sixta 2006).

It is interesting to compare the pulp properties of HWE-3 and ST-1, where the severity of the HWE (Pfactor $=2,020)$ is much greater than that of the ST $(\mathrm{P}-$ factor $=756$ ). The lignin content of the solid residue from HWE-3 is far higher than that from ST (ST-1), although the pentosan removal values for the two treatments are very similar. Under the same kraft pulping conditions, however, the residual alkali concentration of HWE-3 was somewhat surprisingly higher than that of ST-1 (Table 1). Meanwhile, cellulose content, yield and viscosity for HWE-3 were all significantly lower than that for ST-1 (Table 1). The most reasonable explanation for this should attribute to lignin condensation products formed during HWE with severe intensity (Figs. 2, 4, 5). As Sixta (2006) reported, condensed lignin is far less reactive towards alkali than the natural lignin in woody lignocellulose. For kraft pulping of HWE-3, most of the alkali was therefore left to react directly with the cellulose (alkali hydrolysis and peeling reaction), rather than being consumed to remove lignin during kraft pulping.
Thus, it seems possible that antagonistic effects resulting from hemicellulose removal and associated lignin condensation on subsequent kraft pulping were more obvious in HWE than in ST. Traditional, static HWE needs to be replaced with more efficient waterbased prehydrolysis methods (such as ST or subcritical water treatment).

\section{Cellulose refining through ECF bleaching}

As Borrega et al. (2013) described, the cellulose yield at a given residual pentosan and lignin content is another key parameter for the manufacture of dissolving pulp at an industrial scale. A comparison of the results from HWE- and ST-kraft pulping processes is in Fig. 6. Cellulose yields (wt on o.d. bamboo) after conducting the kraft pulping process dramatically decreased for both HWE and ST of bamboo when the pentosan content was below $\sim 3.4 \%$ or kappa number was below $\sim 8.2$. As is known for the production of a high yield of bleached paper-grade pulp in the pulping industry, these results indicate the limitations of kraft pulping for selectively removing non-cellulosic components from prehydrolyzed solid residue and the necessity of additional bleaching sequences.

Because of its high cellulose purity while avoiding the abrupt cellulose yield decrease, ST-2 was selected 


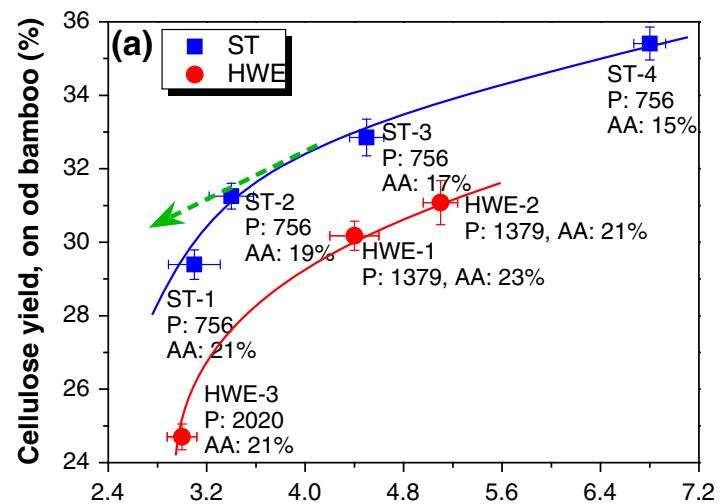

Pentosan content of unbleached pulp (\%, on od pulp)

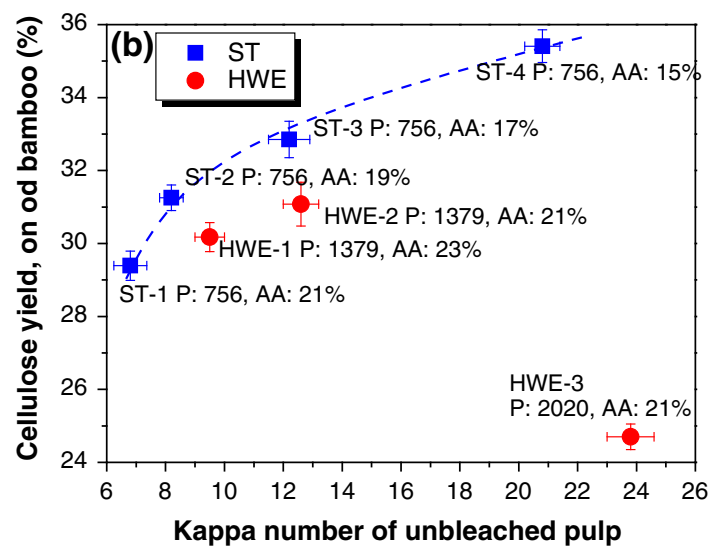

Fig. 6 Comparisons of obtained cellulose yield (wt on o.d. bamboo) from HWE- and ST-kraft pulping processes at a given $\mathbf{a}$ residual pentosan content and $\mathbf{b}$ kappa number

as a relatively optimal unbleached dissolving pulp, and then subjected to further refining through two ECF bleaching sequences. As shown in Table 2 and Supplemental $\mathrm{C}$, increasing the active chlorine charge (ACC) used in $\mathrm{D}_{1}$ resulted in pulps with high alphacellulose content and pulp brightness, and low kappa number, pentosan and ash contents. However, once the ACC used in this bleaching stage was increased beyond $1.90 \%$ (on o.d. pulp), the cellulose viscosity was sharply decreased, although there was no drastic reduction in pentosan content. The results for stage $D_{2}$ showed similar to those seen for $\mathrm{D}_{1}$. Thus, the optimal ACCs used in $D_{1}$ and $D_{2}$ were finally selected as 1.90 and $0.4 \%$, respectively.

The conditions involved in the bleaching stages of $\mathrm{Q}$ and $\mathrm{P}$ were chosen according to our previous study (Luo et al. 2012). Although the addition of $\mathrm{ED}_{2}$ in $\mathrm{D}_{1} \mathrm{ED}_{2}$ and $\mathrm{EQP}$ in DEQP bleaching sequences
Table 2 ECF bleaching of steam PHK pulp for production of high-purity dissolving pulp

\begin{tabular}{|c|c|c|c|c|c|}
\hline \multirow[t]{2}{*}{ Bleaching sequence } & \multicolumn{3}{|c|}{$\mathrm{D}_{1} \mathrm{ED}_{2}$} & \multicolumn{2}{|c|}{$\mathrm{DEQP}^{\mathrm{c}}$} \\
\hline & $\mathrm{D}_{1}$ & $\mathrm{E}$ & $\mathrm{D}_{2}$ & Q & $\mathrm{P}$ \\
\hline Chemical charge $^{\mathrm{a}}(\%)$ & 1.9 & 2.0 & 0.4 & 0.2 & 2.5 \\
\hline $\begin{array}{l}\text { Cellulosic pulp yield }{ }^{\mathrm{a}} \\
(\%)\end{array}$ & 30.3 & 28.1 & 26.6 & 26.5 & 25.7 \\
\hline Lignin content ${ }^{\mathrm{b}}(\%)$ & 0.24 & 0.15 & 0.13 & 0.17 & 0.10 \\
\hline $\begin{array}{l}\text { Alpha-cellulose } \\
\text { content }^{\mathrm{b}}(\%)\end{array}$ & 97.55 & 97.89 & 98.23 & 98.09 & 98.11 \\
\hline Pentosan content ${ }^{\mathrm{b}}(\%)$ & 1.84 & 1.63 & 1.40 & 1.79 & 1.65 \\
\hline Ash content ${ }^{\mathrm{b}}(\%)$ & 0.23 & 0.17 & 0.15 & 0.16 & 0.14 \\
\hline Brightness (\% ISO) & 73.2 & 75.9 & 88.2 & 78.5 & 87.8 \\
\hline $\begin{array}{l}\text { Cellulose viscosity } \\
(\mathrm{mL} / \mathrm{g})\end{array}$ & 927 & 855 & 759 & 807 & 632 \\
\hline
\end{tabular}

${ }^{a}$ On o.d. untreated bamboo

b On o.d. bleached pulp

c The conditions of $\mathrm{D}$ and $\mathrm{E}$ stage conducted in DEQP are same to that of $D_{1}$ and $E$ used in $D_{1} E D_{2}$

increased the pulp brightness, it also greatly reduced the pulp yield and viscosity and did not produce a significant increase in pulp purity (Table 2). A single stage of chlorine dioxide bleaching $\left(\mathrm{D}_{1}\right)$ gave a satisfactory result, essentially meeting the requirements for an acetate-grade pulp with a xylan content lower than $2 \%$, a cellulose content higher than $97 \%$, and an intrinsic viscosity between 600 and $800 \mathrm{~mL} / \mathrm{g}$. A single stage bleaching process also reduces operational costs and capital equipment required for industrial scale production.

Based on the combination of prehydrolysis, alkaline pulping and bleaching technologies, dissolving pulps from several other studies and this work are compared in Table 3. Although a fairly high pulp yield and viscosity were achieved, without bleaching and intensified HWE, water PHK processed aspen wood gave the lowest cellulose purity (Al-Dajani et al. 2009). Under constant alkali pulping and bleaching conditions, the xylan content in bleached pulp can be successfully reduced by significantly increasing the intensity of HWE (Behin and Zeyghami 2009; Borrega et al. 2013) or by adding a small amount of mineral acid as a hydrolysis catalyst (Jahan 2008). However, the viscosities of the corresponding pulps were also slightly decreased (Table 3 ). Although the viscosity loss caused by the above reasons can be 
Table 3 Comparisons of the properties of dissolving pulp originating from different methods and various raw materials

\begin{tabular}{|c|c|c|c|c|c|c|c|c|c|}
\hline $\begin{array}{l}\text { Raw } \\
\text { materials }\end{array}$ & $\begin{array}{l}\text { Methods based on } \\
\text { prehydrolysis, } \\
\text { alkaline pulping and } \\
\text { bleaching }\end{array}$ & $\begin{array}{l}\text { Pulp } \\
\text { yield } \\
(\%)^{\mathrm{a}}\end{array}$ & $\begin{array}{l}\text { Alpha- } \\
\text { cellulose } \\
\text { content } \\
(\%)^{\mathrm{b}}\end{array}$ & $\begin{array}{l}\text { Pentosan } \\
\text { or xylan } \\
\text { content } \\
(\%)^{\mathrm{b}}\end{array}$ & $\begin{array}{l}\text { Lignin } \\
\text { content } \\
(\%)^{\mathrm{b}} / \mathrm{kappa} \\
\text { number }\end{array}$ & $\begin{array}{l}\text { Cellulose } \\
\text { viscosity } \\
(\mathrm{mL} / \mathrm{g})\end{array}$ & $\begin{array}{l}\text { Ash } \\
\text { content } \\
(\%)^{\mathrm{b}}\end{array}$ & $\begin{array}{l}\text { Brightnes } \\
(\% \text { ISO })\end{array}$ & References \\
\hline $\begin{array}{l}\text { Birch } \\
\text { wood }\end{array}$ & Water PHK & 35.1 & $93.9^{\mathrm{c}}$ & 3.1 & $3.0 / 10.6$ & 703 & n.d. & n.d. & $\begin{array}{l}\text { Borrega } \\
\text { et al. } \\
(2013)\end{array}$ \\
\hline $\begin{array}{l}\text { Corn } \\
\text { stalk }\end{array}$ & Water PHK-HEHP & n.d. ${ }^{\mathrm{d}}$ & 94.8 & n.d. & n.d. & 206 & 0.75 & n.d. & $\begin{array}{l}\text { Behin and } \\
\text { Zeyghami } \\
(2009)\end{array}$ \\
\hline $\begin{array}{l}\text { Aspen } \\
\text { wood }\end{array}$ & Water PHK & 38.8 & 88.0 & 4.2 & $0.7 / 6.0$ & 1,125 & 0.4 & n.d. & $\begin{array}{l}\text { Al-Dajani } \\
\text { et al. } \\
\text { (2009) }\end{array}$ \\
\hline \multirow[t]{2}{*}{ Jute fiber } & Acidic PHS-D $\mathrm{O}_{\mathrm{O}} \mathrm{D}_{1}$ & $<31.7$ & 96.1 & n.d. & n.d. & 239 & n.d. & 84.9 & \multirow{2}{*}{$\begin{array}{l}\text { Jahan } \\
\text { (2008) }\end{array}$} \\
\hline & $\begin{array}{l}\text { Acidic PHS (40 \% } \\
\text { EDA)-D } \mathrm{DD}_{1}\end{array}$ & $<31.7$ & 96.2 & n.d. & n.d. & 562 & n.d. & 79.5 & \\
\hline $\begin{array}{l}\text { Green } \\
\text { bamboo }\end{array}$ & Steam PHK-D & 30.3 & 97.6 & 1.8 & 0.2/n.d. & 927 & 0.2 & 73.2 & This study \\
\hline
\end{tabular}

partially eliminated by replacing $\mathrm{NaOH}$ with ethylenediamine (EDA) during the alkali pulping process (Jahan 2008), this modification will increase the operation costs.

It should be noted that, because of the differences in internal structure, chemical composition and chemistry of treatments, viscosities of the pulps from different raw materials have no absolute comparability. However, when we compare tests on one particular material (green bamboo) in this study, better permission of steam compared with liquid water and immediate draining of condensate water actually allow us to prevent extensive lignin condensation, and thus to obtain a more porous solid residue structure and a higher removal of non-cellulosic components (Table 1). Finally, even though a nonwood material was used in this study, a cellulosic pulp with high alpha-cellulose content and pulp viscosity was obtained (Table 2). Although there will need to further increase final cellulosic pulp yield (at present it is only about $30 \%$ ) through integrated optimizing of ST, kraft pulping and ECF bleaching, above results clearly indicate that steam-based PHK-D is promising process, and green bamboo a promising raw material, for production of high purity-grade dissolving pulp.

\section{Conclusions}

As a step towards a forest biorefinery concept, HWEand ST-kraft processes followed by ECF bleaching were compared to produce high purity-grade dissolving pulp from green bamboo. Compared with ST, HWE could be made to remove similar amounts of hemicellulose by increasing the extraction intensity. However, FTIR and SEM measurements showed that severe HWE produced significant lignin condensation, which resulted in dramatic cellulose yield and viscosity loss during subsequent kraft pulping. Although decreasing the intensity of HWE could partially alleviate this adverse effect, it still consumed more AA than the ST-kraft process. Finally, a dissolving pulp with similar properties to acetate-grade pulp was successfully produced from a steam PHK-D process.

Acknowledgments Funding from National Natural Science Foundation of China (No. 31300495), Ministry of Education of China (No. 20123515120018), Fujian Provincial Department of Education (No. JK2012015) and Department of Science and Technology (No. 2013J05041) are gratefully acknowledged. The authors also thank Key Laboratory of biofuels at Qingdao Institute of Bioenergy, Chinese Academy of Sciences for sample characterization based on Open Fundations (No. CASKLB201308). We sincerely appreciate the input from Dr. 
Q. Yang (University of Wisconsin-Madison, UW) and Dr. S. Li (UW, present at KDN Biotech Group, China), who offered valuable suggestions regarding the revision of this paper.

\section{References}

Al-Dajani WW, Tschirner UW, Jensen T (2009) Pre-extraction of hemicelluloses and subsequent kraft pulping. Part II. Acid and autohydrolysis. Tappi J 8(9):30-37

Allen SG, Schulman D, Lichwa J, Antal MJ, Laser M, Lynd LR (2001) A comparison between hot liquid water and steam fractionation of corn fiber. Ind Eng Chem Res 40(13):2934-2941

Amidon TE, Liu S (2009) Water-based woody biorefinery. Biotechnol Adv 27(5):542-550

Bajpai P, Bajpait PK (2001) Development of a process for the production of dissolving kraft pulp using xylanase enzyme. Appita J 54(4):381-384

Behin J, Zeyghami M (2009) Dissolving pulp from corn stalk residue and waste water of Merox unit. Chem Eng J 152(1):26-35

Borrega M, Tolonen LK, Bardot F, Testova L, Sixta H (2013) Potential of hot water extraction of birch wood to produce high-purity dissolving pulp after alkaline pulping. Bioresour Technol 135:665-671

Colom X, Carrillo F (2002) Crystallinity changes in lyocell and viscose-type fibres by caustic treatment. Eur Polym J 38(11):2225-2230

Duarte GV, Ramarao BV, Amidon TE, Ferreira PT (2011) Effect of hot water extraction on hardwood kraft pulp fibers (Acer saccharum, sugar maple). Ind Eng Chem Res 50(17):9949-9959

Fink HP, Weigel P, Ganster J, Rihm R, Puls J, Sixta H, Parajo JC (2004) Evaluation of new organosolv dissolving pulps. Part II: structure and NMMO processability of the pulps. Cellulose 11(1):85-98

Froschauer C, Hummel M, Iakovlev M, Roselli A, Schottenberger H, Sixta H (2013) Separation of hemicellulose and cellulose from wood pulp by means of ionic liquid/cosolvent systems. Biomacromolecules 14(6):1741-1750

Helmerius J, von Walter JV, Rova U, Berglund KA, Hodge DB (2010) Impact of hemicellulose pre-extraction for bioconversion on birch Kraft pulp properties. Bioresour Technol 101(15):5996-6005

Hinck J, Casebier R, Hamilton J (1985) Dissolving pulp manufacture. In: Kocurek MJ, Ingruber OV, Wong A (eds) Sulfite science and technology, vol 4, 3rd edn. TAPPI, Atlanta, pp 213-243

Ibarra D, Köpcke V, Ek M (2009) Exploring enzymatic treatments for the production of dissolving grade pulp from different wood and non-wood paper grade pulps. Holzforschung 63(6):721-730

Jahan MS (2008) Studies on the effect of prehydrolysis and amine in cooking liquor on producing dissolving pulp from jute (Corchorus capsularis). Wood Sci Technol 43(3-4):213-224

Kemppainen K, Inkinen J, Uusitalo J, Nakari-Setälä T, Siikaaho M (2012) Hot water extraction and steam explosion as pretreatments for ethanol production from spruce bark. Bioresour Technol 117:131-139
Köpcke V, Ibarra D, Larsson PT, Ek M (2010) Optimization of treatment sequences for the production of dissolving pulp from birch kraft pulp. Nord Pulp Pap Res J 25(1):31-38

Laser M, Schulman D, Allen SG, Lichwa J, Antal MJ Jr, Lynd LR (2002) A comparison of liquid hot water and steam pretreatments of sugar cane bagasse for bioconversion to ethanol. Bioresour Technol 81(1):33-44

Leschinsky M, Zuckerstätter G, Weber HK, Patt R, Sixta H (2008a) Effect of autohydrolysis of Eucalyptus globulus wood on lignin structure. Part 1: comparison of different lignin fractions formed during water prehydrolysis. Holzforschung 62(6):645-652

Leschinsky M, Zuckerstätter G, Weber HK, Patt R, Sixta H (2008b) Effect of autohydrolysis of Eucalyptus globulus wood on lignin structure. Part 2: influence of autohydrolysis intensity. Holzforschung 62(6):653-658

Li HM, Saeed A, Jahan MS, Ni YH, Van Heiningen ARP (2010) Hemicellulose removal from hardwood chips in the prehydrolysis step of the kraft-based dissolving pulp production process. J Wood Chem Technol 30(1):48-60

Liu CF, Xu F, Sun JX, Ren JL, Curling S, Sun RC, Fowler P, Baird MS (2006) Physicochemical characterization of cellulose from perennial ryegrass leaves (Lolium perenne). Carbohydr Res 341(16):2677-2687

Luo XL, Hu HC, Chai XS, Cao SL, Huang LL, Chen LH (2012) Improving bleached pulp yield and paper strength properties of eucalyptus through integrating kraft pulping to high kappa number and oxygen delignification. J Biobased Mater Bio 6(5):531-537

Luo XL, Liu J, Zhan HY, Cao SL, Huang LL, Chen LH (2013a) Prediction model and in-digester control of residual alkali content in black liquor during kraft pulping of eucalyptus. J Biobased Mater Bioenergy 7(5):559-565

Luo XL, Ma XJ, Hu HC, Li CH, Cao SL, Huang LL, Chen LH (2013b) Kinetic study of pentosan solubility during heating and reacting processes of steam treatment of green bamboo. Bioresour Technol 130:769-776

Ma XJ, Cao SL, Lin L, Luo XL, Chen LH, Huang LL (2013) Surface characterizations of bamboo substrates treated by hot water extraction. Bioresour Technol 136:757-760

Ma XJ, Huang LL, Chen YX, Chen LH (2011) Preparation of bamboo dissolving pulp for textile production. Part 1 . Study on prehydrolysis of green bamboo for producing dissolving pulp. Bioresource 6(2):1428-1439

Montane D, Farriol X, Salvado J, Jollez P, Chornet E (1998) Application of steam explosion to the fractionation and rapid vapor-phase alkaline pulping of wheat straw. Biomass Bioenerg 14(3):261-276

Pandey KK (1999) A study of chemical structure of soft and hardwood and wood polymers by FTIR spectroscopy. J Appl Polym Sci 71(12):1969-1975

Perez-Cantu L, Schreiber A, Schütt F, Saake B, Kirsch C, Smirnova I (2013) Comparison of pretreatment methods for rye straw in the second generation biorefinery: effect on cellulose, hemicellulose and lignin recovery. Bioresour Technol 142:428-435

Puls J, Janzon R, Saake B (2006) Comparative removal of hemicelluloses from paper pulps using nitren, cuen, $\mathrm{NaOH}$, and $\mathrm{KOH}$. Lenzinger Berichte 86:63-70

Saeed A, Jahan MS, Li HM, Liu Z, Ni YH, Van Heiningen ARP (2012) Mass balances of components dissolved in the 
prehydrolysis liquor of kraft-based dissolving pulp production process from Canadian hardwoods. Biomass Bioenergy 39:14-19

Sannigrahi P, Kim DH, Jung S, Ragauskas A (2011) Pseudolignin and pretreatment chemistry. Energy Environ Sci 4(4):1306-1310

Sixta H (2006) Handbook of pulp. Wiley-VCH, Weinheim, pp 325-365 and 1009-1067

Sixta H, Iakovlev M, Testova L, Roselli A, Hummel M, Borrega M, Heiningen A, Froschauer C, Schottenberger H (2013) Novel concepts of dissolving pulp production. Cellulose 20(4):1547-1561

Van Heiningen ARP (2006) Converting a kraft pulp mill into an integrated forest biorefinery. Pulp Pap-Canada 107(6):38-43
Walton SL, Hutto D, Genco JM, Van Walsum GP, Van Heiningen ARP (2010) Pre-extraction of hemicelluloses from hardwood chips using an alkaline wood pulping solution followed by kraft pulping of the extracted wood chips. Ind Eng Chem Res 49(24):12638-12645

Wang K, Jiang JX, Xu F, Sun RC (2009) Influence of steaming explosion time on the physic-chemical properties of cellulose from Lespedeza stalks (Lespedeza crytobotrya). Bioresour Technol 100(21):5288-5294

Yoon SH, Van Heiningen ARP (2008) Kraft pulping and papermaking properties of hot-water pre-extracted loblolly pine in an integrated forest products biorefinery. Tappi J 7(7):22-27 